\begin{tabular}{|c|c|}
\hline Title & Stature estimation from anatomical landmarks in femur using postmortem $\mathrm{CT}$ \\
\hline Author(s) & $\begin{array}{l}\text { Baba, Miho; Hyodoh, Hideki; Okazaki, Shunichiro; Shimizu, Juny a; Mizuo, Keisuke; Rokukawa, Masumi; Watanabe, } \\
\text { Satoshi; Matoba, Kotaro; Inoue, Hiromasa }\end{array}$ \\
\hline Citation & $\begin{array}{l}\text { Journal of forensic radiology and imaging, } 7,28.32 \\
\text { https://doi.org/10.1016/.jofri.2016.11.002 }\end{array}$ \\
\hline Issue Date & $2016-12$ \\
\hline Doc URL & http:/hdl.handle.net/2115/67744 \\
\hline Rights & $\begin{array}{l}\text { (9 2016. This manuscript version is made available under the CC-BY-NC-ND } 4.0 \text { license } \\
\text { http://reativecommons.org/icenses/by-nc-nd/4.0/ }\end{array}$ \\
\hline Rights(URL) & http://creativecommons.org/icenses/by-nc-nd/4.0/ \\
\hline Type & article (author version) \\
\hline File Information & JForensicRadiollmaging7_28.pdf \\
\hline
\end{tabular}

Instructions for use 


\section{Stature estimation from anatomical landmarks in femur using postmortem CT}

Miho Baba1), Hideki Hyodoh'12), Shunichiro Okazaki' ${ }^{1}$, Junya Shimizu' ${ }^{1)}$ Keisuke Mizuo $^{1)}$, Masumi Rokukawa ${ }^{1)}$, Satoshi Watanabe ${ }^{1)}$, Kotaro Matoba ${ }^{3)}$, Hiromasa Inoue $^{1)}$

1) Department of Legal Medicine, Sapporo Medical University

2) Center for Cause of Death Investigation, Hokkaido University Graduate School of Medicine

3) Department of Forensic Medicine, Hokkaido University Graduate School of Medicine

Corresponding author

Hideki Hyodoh MD, PhD.

Specially Appointed Associate Professor

Center for Cause of Death Investigation, Hokkaido University Graduate School of Medicine

Phone: +81-11-706-5905

Fax: +81-11-706-7860

e-mail: hyodoh@med.hokudai.ac.jp 


\section{Highlight}

1) The stature using anatomical landmark (adductor tubercle) shows high coefficient of determination.

2) The regression equations using partial femur measurement show reliable estimated stature.

3) One formula could be used to estimate the cadaver's stature in spite of sex difference. 
Stature estimation from anatomical landmarks in femur using postmortem CT 


\begin{abstract}
Objective: The present study aims to assess the correlation between stature and partial femur measurements in Japanese population, using three-dimensional (3D) computed tomographic (CT) images.

Method: A total of 195 cadavers (105 males, 90 females) underwent postmortem CT scanning and subsequent forensic autopsy between April 2013 and June 2014. Five femur length measurements were taken from 3D CT volume rendering (VR) images according to three anatomical landmarks: the greater trochanter, the lesser trochanter, and the adductor tubercle. The correlations between stature and each of the femur length measurements were assessed with Spearman's rank correlation test, and showed significant correlations between stature and femur length measurements.

Results: Using a mixed-sex regression formula, the $\mathrm{R}^{2}$ was from 0.644 to 0.766 and actual difference was less than $4.6 \mathrm{~cm}$.

Conclusion: Present study showed that femur length measurements, according to the anatomical landmarks obtained from 3DCT VR images, were useful for estimation of the stature, particularly in cases when a total femur bone was not available.
\end{abstract}

\title{
Keywords
}

- Postmortem CT

- Femur

- Limb bone length

- Regression analysis

- Stature estimation 


\section{Introduction}

Personal identification is one of the important aspects of postmortem imaging used in practical legal medicine and forensic radiology. And determining the stature is the first step to identifying physical characteristics. Ideally, the stature is measured from the top of the skull to the bottom of the foot without lack of any body part. However, the task of identification is challenging when decomposed, dismembered, or only partial bone remains are recovered. A number of studies have demonstrated the estimation of stature using intact bones [1-3]. However in practical cases, if a fragmented bone was found, it was difficult to use these formulae without assuming total bone length, so that it what was done in forensic investigation.

A recent topic of interest in legal medicine is postmortem imaging using computed tomography (CT) [4-7] and cases of using bone images for stature estimation also have been reported [3, 8, 9]. Nishino [1] reported formulae to estimate stature using humerus, radius, ulna, femur, tibia, and fibula in postmortem CT (PMCT). However, if the bone showed no significant characteristic finding regarding sex difference, the reported sex related formula cannot be used.

If the use of a fragmented bone for stature estimation using PMCT could be enabled, and additionally, if a sex-independent formula could be established, it should provide a useful and objective method in many cases of personal identification. The purpose of our study was to investigate formulae of stature estimation using femur length measurements according to the anatomical landmarks, as well as to investigate the sex-independent stature estimate equations using 3DCT images in the current Japanese population. 


\section{Materials and methods}

The study was approved by our institutional ethics committee. Between April 2013 and June 2014, all autopsy cases were evaluated, and if the cadaver had distracted or missing part to affect the stature measurement, those were excluded from this study. In result, 195 cadavers (105 males; 90 females, 20 - 94 (mean 61.4) years old) were enrolled in this study. All cadavers were transported to our department for investigation by PMCT and subsequent forensic autopsy. At the beginning of the autopsy, the cadaver stature was measured by scale (actual stature). If spinal scoliosis was detected after autopsy, no adjustment was used.

On PMCT, all bodies were imaged in a sealed body bag in the supine position with the arms adjacent to the body using a 64-slice multi-detector row CT scanner (Aquilion CX, Toshiba, Tochigi, Japan) using the following protocol: neck to foot, 120 $\mathrm{kV}, 50-400 \mathrm{~mA}$ (variable $\mathrm{mA}$ ), $0.5 \mathrm{~s} /$ rotation, pitch factor 0.828 , configuration 0.5 $\mathrm{x} 32$, reconstruction $0.5 \mathrm{~mm}$. Image data were processed on a workstation (Synapse Vincent V3.3.0003, Fujifilm Medical, Tokyo, Japan) to obtain volume-rendered (VR) images. For assessment, data for both femurs were extracted from the VR data. According to the femur anatomical landmarks (Fig. 1A and 1B), the greater trochanter, the lesser trochanter, and the adductor tubercle, five femur parameters (distance from top level of head of femur to adductor level length (top-A), from the greater trochanter level to adductor level length (GT-A), from midpoint level of trochanters to adductor level length (MT-A), from the lesser trochanter level to adductor level length (LT-A), and the maximum femur length (MF)) were measured using VR data (Fig. 1C). The measurements of all images were performed successively 3 times with 2 months intervals by one operator.

Descriptive analyses were performed to obtain the mean, standard deviation (SD), and range for age, actual stature, and the femur measurement parameters for the mixed-sex group as well as for the male and female groups separately. The collected data were analyzed on a personal computer using JMP (SAS Institute Inc., North Carolina, USA, version 11.0.0) software with a Spearman's rank correlation test for the comparison between the estimated stature calculated using femur measured parameters (m-TA, l-TA, MF) and actual stature measurement, and with a Student's t-test to compare the operator dependency. Differences where $\mathrm{p}<0.05$ were considered statistically significant. 
Fig 1 femur anatomical landmarks

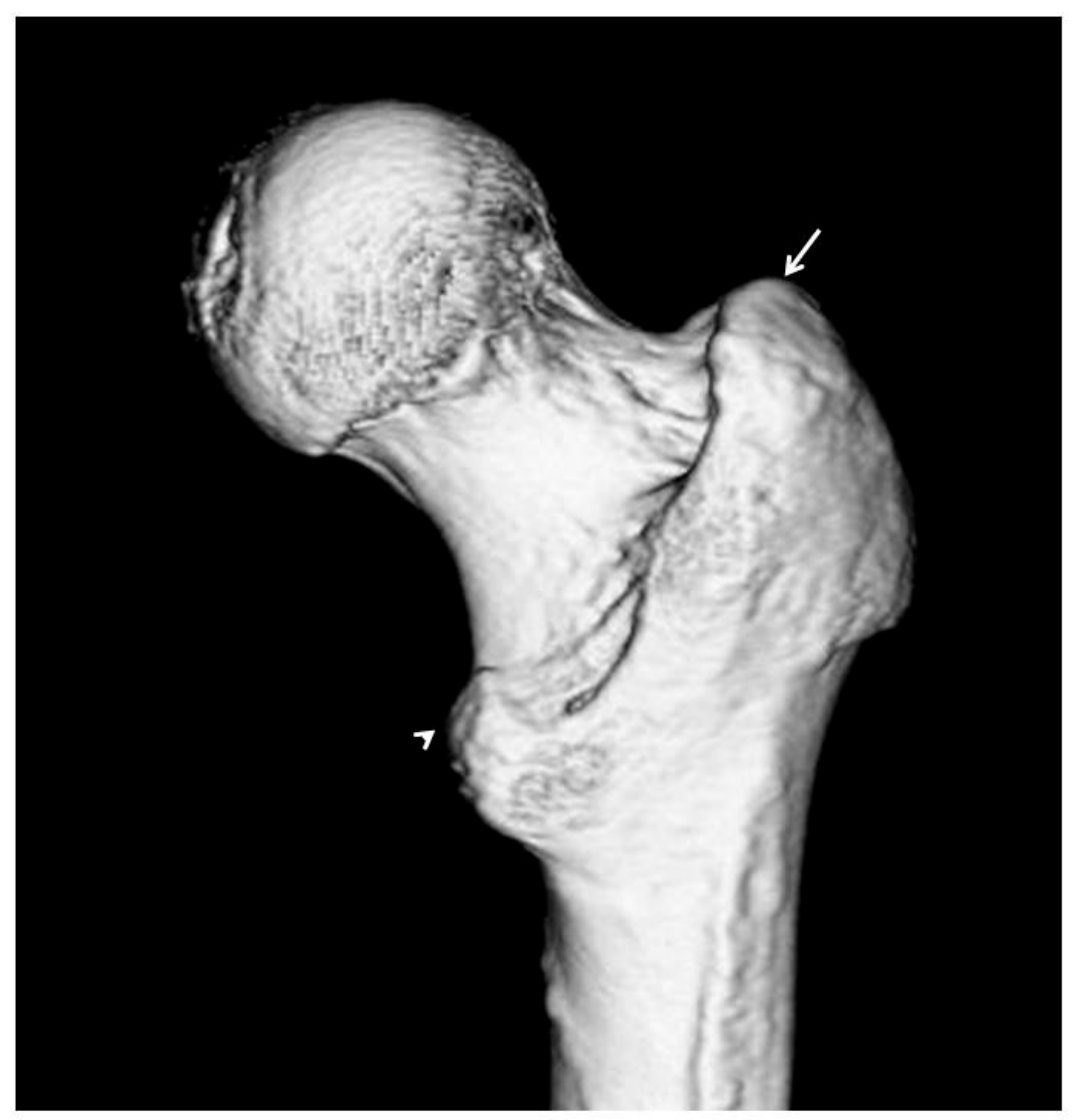

Fig 1a proximal femur

Arrow shows the greater trochanter

Arrowhead shows the lesser trochanter 


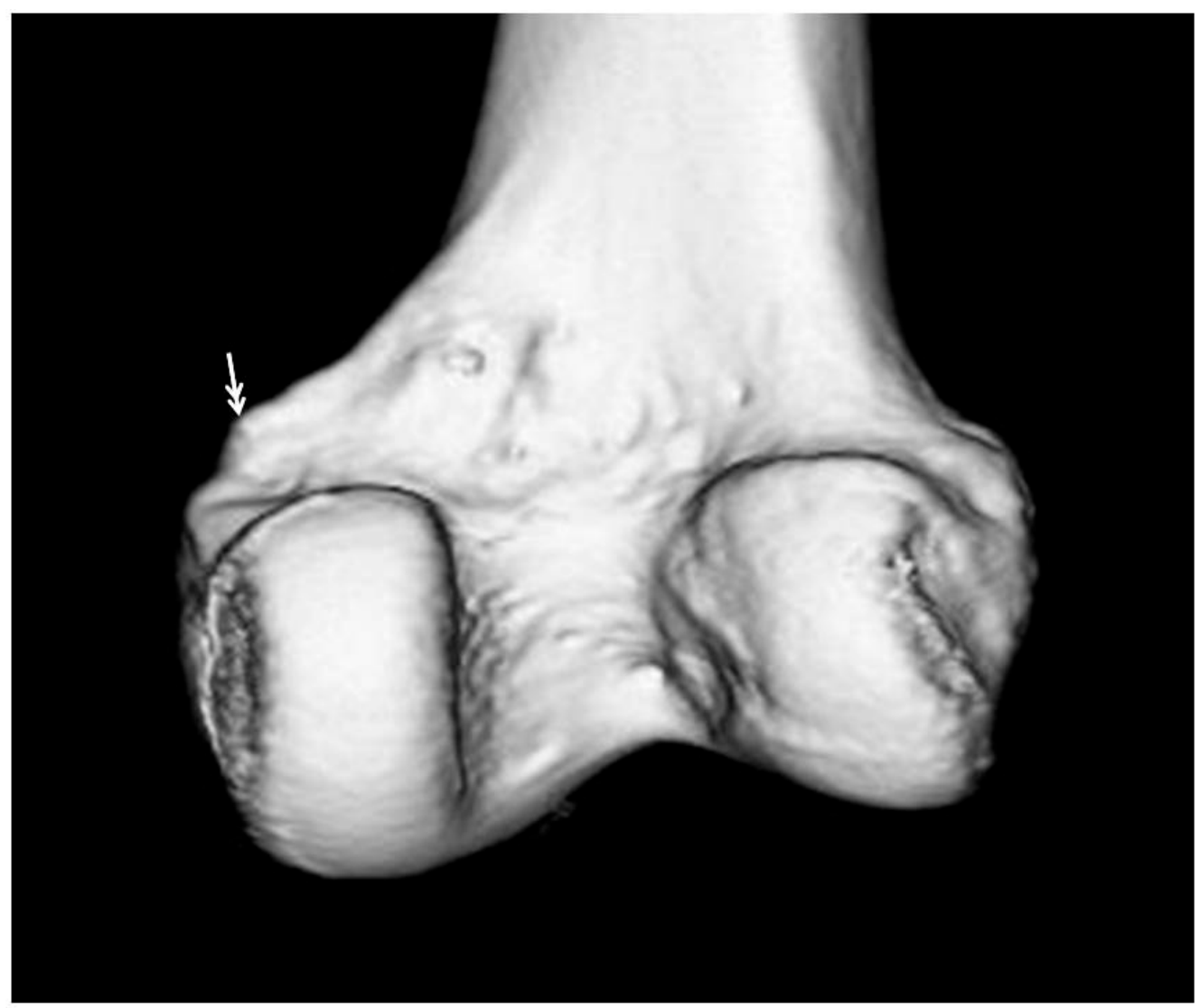

Fig $1 b$ distal femur

Double arrow shows the adductor tubercle 


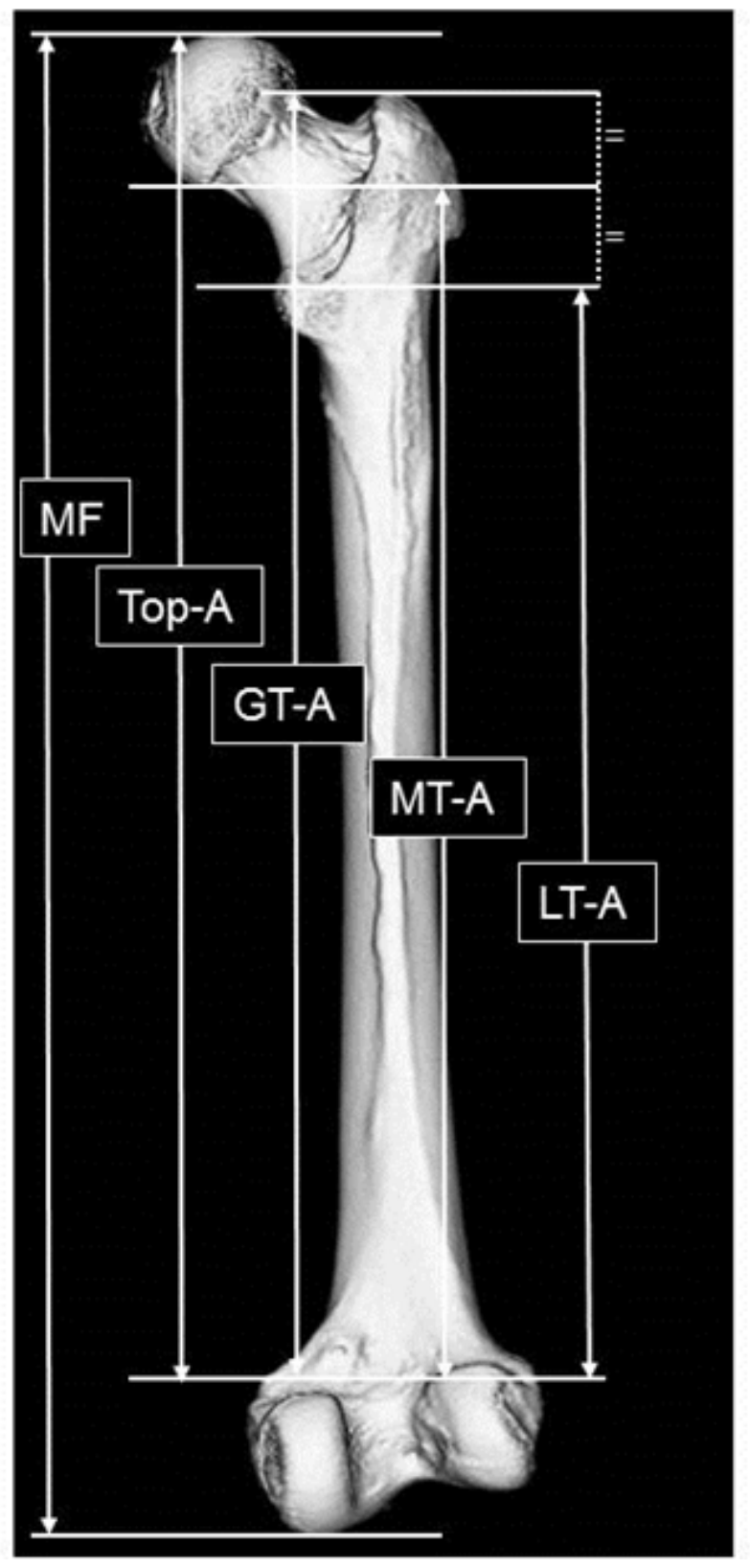

Fig 1c femur measurements

According to the anatomical landmarks, the femur lengths are measured on 3DCT.

Before measurement, the femur long axis is placed perpendicular.

MF: maximum femur length

Top-A: from top level of head of femur to adductor level length

GT-A: from greater trochanter level to adductor level length

MT-A: from midpoint level of trochanters to adductor level length

LT-A: from lesser trochanter level to adductor level length 


\section{Results}

The descriptive statistics are presented in Table 1. Student's $t$-tests revealed that the mean values for actual stature and the estimated stature using femur measurements were significantly greater for the male subjects than for the female subjects.

Table 1.

Descriptive statistics of age, actual stature (AS), and femur length measurements.

\begin{tabular}{|c|c|c|c|c|c|c|c|}
\hline & & \multicolumn{2}{|c|}{ all $(\mathrm{n}=195)$} & \multicolumn{2}{|c|}{ Male $(\mathrm{n}=105)$} & \multicolumn{2}{|c|}{ Female $(\mathrm{n}=90)$} \\
\hline & & range & mean \pm SD & range & mean $\pm \mathrm{SD}$ & range & mean $\pm \mathrm{SD}$ \\
\hline age & & $20-94$ & $61.3 \pm 18.4$ & $20-94$ & $58.9 \pm 16.2$ & $21-93$ & $64 \pm 20.4$ \\
\hline actual height & & $136.0-190.0$ & $159.5 \pm 10.0$ & $143.7-190.0$ & $164.8 \pm 7.8$ & $136.0-180.0$ & $153.4 \pm 8.6$ \\
\hline \multirow[t]{3}{*}{ MF } & right & $329.1-530.6$ & $418.5 \pm 30.2$ & $355.1-530.6$ & $433.0 \pm 26.1$ & $329.1-483.9$ & $401.6 \pm 25.6$ \\
\hline & left & $334.7-526.1$ & $419.2 \pm 30.4$ & $251.3-391.0$ & $311.7 \pm 22.4$ & $334.7-472.0$ & $401.9 \pm 24.9$ \\
\hline & both & $332.1-528.1$ & $418.9 \pm 30.2$ & $356.6-528.1$ & $433.5 \pm 26.3$ & $332.1-477.9$ & $401.8 \pm 25.2$ \\
\hline \multirow[t]{3}{*}{ Top-A } & right & $291.6-481.0$ & $375.1 \pm 27.7$ & $318.2-481.0$ & $387.9 \pm 24.7$ & $291.6-430.8$ & $361.7 \pm 24.1$ \\
\hline & left & $298.7-467.9$ & $376.0 \pm 27.9$ & $321.1-467.9$ & $388.2 \pm 24.6$ & $298.7-438.6$ & $361.8 \pm 24.7$ \\
\hline & both & $295.2-474.5$ & $375.9 \pm 27.7$ & $319.7-474.5$ & $388.0 \pm 24.6$ & $295.2-429.9$ & $361.7 \pm 24.3$ \\
\hline \multirow[t]{3}{*}{ GT-A } & right & $286.7-453.4$ & $357.5 \pm 26.3$ & $276.1-421.0$ & $339.6 \pm 22.1$ & 265.4-338.4 & $317.8 \pm 22.3$ \\
\hline & left & $296.2-461.5$ & $359.1 \pm 26.6$ & $277.6-424.6$ & $341.1 \pm 23.3$ & $270.8-382.6$ & $318.4 \pm 21.1$ \\
\hline & both & $293.3-456.5$ & $358.3 \pm 26.2$ & $277.3-422.4$ & $340.4 \pm 22.6$ & $268.2-385.5$ & $318.1 \pm 21.6$ \\
\hline \multirow[t]{3}{*}{ MT-A } & right & $265.4-421.0$ & $329.6 \pm 24.7$ & $276.1-421.0$ & $339.6 \pm 22.1$ & $265.4-338.4$ & $317.8 \pm 22.3$ \\
\hline & left & $270.8-424.6$ & $330.7 \pm 25.0$ & $277.6-424.6$ & $341.1 \pm 23.3$ & $270.8-382.6$ & $318.4 \pm 21.1$ \\
\hline & both & $268.2-422.4$ & $330.1 \pm 24.7$ & $277.3-422.4$ & $340.4 \pm 22.6$ & $268.2-385.5$ & $318.1 \pm 21.6$ \\
\hline \multirow[t]{3}{*}{ LT-A } & right & $239.3-389.8$ & $301.6 \pm 23.6$ & $255.2-389.8$ & $310.7 \pm 21.2$ & $239.3-358.7$ & $291.0 \pm 21.7$ \\
\hline & left & $245.4-391.0$ & $302.3 \pm 24.0$ & $251.3-391.0$ & $311.7 \pm 22.4$ & $245.4-353.4$ & $291.2 \pm 20.8$ \\
\hline & both & $242.4-389.8$ & $301.9 \pm 23.7$ & 253.9-389.8 & $311.2 \pm 21.7$ & $242.4-355.9$ & $291.1 \pm 21.1$ \\
\hline
\end{tabular}

The simple linear regression equations derived from actual stature and 5 femur measurement parameters in mixed-sex, male, and female groups, are presented in Table 2. There were positive correlations between actual stature and each of the femur measurement parameters for all subjects. The $\mathrm{R}^{2}$ were from 0.516 to 0.766 , and the highest coefficient of determination was for the mixed-sex group $\left(\mathrm{R}^{2}\right.$ were from 0.644 to 0.766 ). The mean differences were from 3.6 to $4.3 \mathrm{~cm}$ in comparing each estimated stature to actual stature, and the male group presented the lowest difference range (from 3.6 to $3.9 \mathrm{~cm}$ ). 
Table 2.

The simple linear regression equations

\begin{tabular}{|c|c|c|c|c|c|c|c|}
\hline \multirow[t]{2}{*}{ group } & \multicolumn{2}{|c|}{ variable } & \multirow[t]{2}{*}{ regression formula $(\mathrm{cm})$} & \multirow[t]{2}{*}{$\mathrm{R}^{2}$} & \multicolumn{3}{|c|}{ difference } \\
\hline & & & & & mean & \pm & $\mathrm{SD}$ \\
\hline \multirow{15}{*}{$\begin{array}{l}\text { Mixed- } \\
\text { sex }\end{array}$} & $\mathrm{MF}$ & right & $\mathrm{AS}=41.90+2.81 * \mathrm{MF}$ & 0.728 & 4.0 & \pm & 3.3 \\
\hline & & left & $\mathrm{AS}=42.10+2.80 * \mathrm{MF}$ & 0.729 & 4.0 & \pm & 3.3 \\
\hline & & bilateral & $\mathrm{AS}=41.44+2.82 * \mathrm{MF}$ & 0.732 & 4.0 & \pm & 3.3 \\
\hline & Top-A & right & $\mathrm{AS}=43.44+3.09 *$ Top $-\mathrm{A}$ & 0.738 & 4.0 & \pm & 3.1 \\
\hline & & left & $\mathrm{AS}=44.18+3.07 *$ Top $-\mathrm{A}$ & 0.740 & 4.0 & \pm & 3.1 \\
\hline & & bilateral & $\mathrm{AS}=42.93+3.10 *$ Top $-\mathrm{A}$ & 0.745 & 4.0 & \pm & 3.1 \\
\hline & GT-A & right & $\mathrm{AS}=49.97+3.06 * \mathrm{GT}-\mathrm{A}$ & 0.654 & 4.6 & \pm & 3.6 \\
\hline & & left & $\mathrm{AS}=51.43+3.01 * \mathrm{GT}-\mathrm{A}$ & 0.644 & 4.6 & \pm & 3.7 \\
\hline & & bilateral & $\mathrm{AS}=49.19+3.08 * \mathrm{GT}-\mathrm{A}$ & 0.658 & 4.6 & \pm & 3.6 \\
\hline & MT-A & right & $\mathrm{AS}=49.37+3.34 * \mathrm{MT}-\mathrm{A}$ & 0.688 & 4.4 & \pm & 3.4 \\
\hline & & left & $\mathrm{AS}=50.29+3.30 * \mathrm{MT}-\mathrm{A}$ & 0.687 & 4.3 & \pm & 3.5 \\
\hline & & bilateral & $\mathrm{AS}=48.94+3.35 * \mathrm{MT}-\mathrm{A}$ & 0.693 & 4.3 & \pm & 3.4 \\
\hline & LT-A & right & $\mathrm{AS}=52.92+0.54 * \mathrm{LT}-\mathrm{A}$ & 0.700 & 4.3 & \pm & 3.4 \\
\hline & & left & $\mathrm{AS}=54.07+3.49 * \mathrm{LT}-\mathrm{A}$ & 0.705 & 4.3 & \pm & 3.3 \\
\hline & & bilateral & $\mathrm{AS}=52.47+3.55 * \mathrm{LT}-\mathrm{A}$ & 0.709 & 4.2 & \pm & 3.3 \\
\hline \multirow{15}{*}{ Male } & $\mathrm{MF}$ & right & $\mathrm{AS}=61.03+2.40 * \mathrm{MA}$ & 0.650 & 3.6 & \pm & 2.9 \\
\hline & & left & $\mathrm{AS}=62.36+2.36 * \mathrm{MA}$ & 0.655 & 3.6 & \pm & 2.8 \\
\hline & & bilateral & $\mathrm{AS}=61.18+2.39 * \mathrm{MA}$ & 0.656 & 3.6 & \pm & 2.9 \\
\hline & Top-A & right & $\mathrm{AS}=65.85+2.55 *$ Top $-\mathrm{A}$ & 0.661 & 3.6 & \pm & 2.7 \\
\hline & & left & $\mathrm{AS}=65.47+2.56 *$ Top $-\mathrm{A}$ & 0.658 & 3.6 & \pm & 2.7 \\
\hline & & bilateral & $\mathrm{AS}=64.70+2.58 *$ Top $-\mathrm{A}$ & 0.666 & 3.6 & \pm & 2.7 \\
\hline & GT-A & right & $\mathrm{AS}=71.30+2.54 * \mathrm{GT}-\mathrm{A}$ & 0.586 & 4.1 & \pm & 2.9 \\
\hline & & left & $\mathrm{AS}=76.11+2.39 * \mathrm{GT}-\mathrm{A}$ & 0.581 & 4.1 & \pm & 2.9 \\
\hline & & bilateral & $\mathrm{AS}=72.37+2.50 * \mathrm{GT}-\mathrm{A}$ & 0.592 & 4.0 & \pm & 2.9 \\
\hline & MT-A & right & $\mathrm{AS}=70.78+2.77 *$ MT-A & 0.622 & 3.9 & \pm & 2.8 \\
\hline & & left & $\mathrm{AS}=74.58+2.65 * \mathrm{MT}-\mathrm{A}$ & 0.631 & 3.8 & \pm & 2.8 \\
\hline & & bilateral & $\mathrm{AS}=72.04+2.73 * \mathrm{MT}-\mathrm{A}$ & 0.631 & 3.8 & \pm & 2.7 \\
\hline & LT-A & right & $\mathrm{AS}=77.47+2.80 * \mathrm{LT}-\mathrm{A}$ & 0.656 & 3.8 & \pm & 2.7 \\
\hline & & left & $\mathrm{AS}=74.59+0.29 * \mathrm{LT}-\mathrm{A}$ & 0.642 & 3.7 & \pm & 2.6 \\
\hline & & bilateral & $\mathrm{AS}=74.99+2.89 * \mathrm{LT}-\mathrm{A}$ & 0.652 & 3.7 & \pm & 2.6 \\
\hline \multirow{15}{*}{ Female } & $\mathrm{MF}$ & right & $\mathrm{AS}=47.28+2.64 * \mathrm{MA}$ & 0.615 & 4.2 & \pm & 3.4 \\
\hline & & left & $\mathrm{AS}=44.62+2.71 * \mathrm{MA}$ & 0.607 & 4.2 & \pm & 3.5 \\
\hline & & bilateral & $\mathrm{AS}=45.11+2.70 * \mathrm{MA}$ & 0.617 & 4.1 & \pm & 3.4 \\
\hline & Top-A & right & $\mathrm{AS}=46.98+2.94 *$ Top $-\mathrm{A}$ & 0.672 & 3.9 & \pm & 3.0 \\
\hline & & left & $\mathrm{AS}=49.22+2.88 *$ Top $-\mathrm{A}$ & 0.682 & 3.9 & \pm & 2.9 \\
\hline & & bilateral & $\mathrm{AS}=47.10+2.94 *$ Top $-\mathrm{A}$ & 0.682 & 3.9 & \pm & 2.9 \\
\hline & GT-A & right & $\mathrm{AS}=59.72+2.72 * \mathrm{GT}-\mathrm{A}$ & 0.542 & 4.6 & \pm & 3.6 \\
\hline & & left & $\mathrm{AS}=55.59+2.83 * \mathrm{GT}-\mathrm{A}$ & 0.516 & 4.6 & \pm & 3.9 \\
\hline & & bilateral & $\mathrm{AS}=55.89+2.82 * \mathrm{GT}-\mathrm{A}$ & 0.539 & 4.5 & \pm & 3.7 \\
\hline & MT-A & right & $\mathrm{AS}=57.33+3.02 *$ MT-A & 0.610 & 4.3 & \pm & 3.3 \\
\hline & & left & $\mathrm{AS}=52.73+3.16 * \mathrm{MT}-\mathrm{A}$ & 0.594 & 4.3 & \pm & 3.5 \\
\hline & & bilateral & $\mathrm{AS}=53.93+3.13 *$ MT-A & 0.609 & 4.2 & \pm & 3.4 \\
\hline & LT-A & right & $\mathrm{AS}=59.84+3.21 * \mathrm{LT}-\mathrm{A}$ & 0.655 & 4.1 & \pm & 3.0 \\
\hline & & left & $\mathrm{AS}=56.42+3.33 * \mathrm{LT}-\mathrm{A}$ & 0.642 & 4.1 & \pm & 3.0 \\
\hline & & bilateral & $\mathrm{AS}=56.92+3.31 * \mathrm{LT}-\mathrm{A}$ & 0.657 & 4.1 & \pm & 3.0 \\
\hline
\end{tabular}


Comparing the difference between the estimated stature using mixed-sex bilateral equation and actual stature, there were no statistical difference in all equations (MF ( $\mathrm{p}=0.1660)$, Top-A $(\mathrm{p}=0.5501)$, GT-A $(\mathrm{p}=0.8298)$, MT-A $(\mathrm{p}=0.6080)$, and LT-A $(\mathrm{p}=0.7551))$. 


\section{Discussion}

Stature measurement is the first step towards establishing personal identification in the practice of legal medicine, and when only a partial bone remains, a forensic pathologist is required to estimate stature from the remaining bone with some reliance on intuition. Some authors have attempted to develop formulae to estimate stature from different bones [3, 10-15]. However the femoral measurements were shown to have an important role in body height estimation [16]. In this study, besides the reported total length of femur bone, the partial bone lengths according to the anatomical landmarks were evaluated, and further confirmed the high correlation, using simple linear regression equations. This is the first report to estimate the stature using femur anatomical landmarks (adductor tubercle and trochanters), and shows high coefficients of determination ( $\mathrm{R}^{2}$ was from 0.516 to 0.766), so that these regression equations could be useful for establishing the identity of an individual in forensic investigation.

Some authors have attempted to develop formulae to estimate stature according to the sex difference. But if the cadaver's gender was not confirmed by anatomical characteristics, it was impossible to select gender-dependent regression equations. Hishmat et al. [16] reported that in stature estimation using individual bone parameters, the accuracies for mixed-sex groups were higher than for male and female groups, and the accuracy of stature estimation is not improved by preliminary sex discrimination. In this study, using the mixed-sex group formula resulted in a higher coefficient of determination ( $\mathrm{R}^{2}$ from 0.644 to 0.766 ) than the male or female group formula, and the actual measurement error range was less than $4.5 \mathrm{~cm}$. Therefore, it is strongly suggested that discrimination by sex provides no advantage in stature estimation using bone parameters.

In this study, 5 parameters were measured from one femur bone. In obtaining the results, 10 parameters were measured, using both sides of the femurs. In addition, in comparing 10 parameters, there was no significant difference in the estimated stature. Hishmat et al [16] reported that the measurements of bilateral bones showed no significant difference for femur, and the maximum lengths highly correlated with the stature both in male and female. Beside their report, which was concordant with our results, the estimation error range from actual stature were MF4.0 $\pm 3.3 \mathrm{~cm}$, Top-A $4.0 \pm 3.1 \mathrm{~cm}$, GT-A $4.6 \pm 3.7 \mathrm{~cm}$, MT-A $4.3 \pm 3.4 \mathrm{~cm}$, and LT-A $4.2 \pm 3.3 \mathrm{~cm}$. Therefore, estimating statures using multiple measured parameters 
may have an advantage in estimating it more exactly than only one measurement method.

Some authors have developed formulae by measuring percutaneous length, without baring bone [17-20]. Others have reported on using X-rays to selectively depict bone length for use in estimating stature [10, 21]. However, X-rays provide a profile view, so it is difficult to measure the maximum length without considerable error range when the bone long axis is tilted. However, 3DCT can be easily employed for extracting a bone image. In addition, the difference between the virtual and manual measurements using skeletonized dry bones is less than $2 \mathrm{~mm}$ [2]. Furthermore, CT data is available after the corpse is no longer accessible, so it makes it possible to obtain the same result in any place and at any time [22]. Thus, 3D CT image is thought to have useful advantages in objective evaluation.

Some authors reported that a different formula is needed for each ethnic group [13, 23]. Mladenovic et al [22] reported that anatomical structure is different between Asia and Europe, so it is reasonable to develop different formulae in respective ethnic groups. If CT study was employed in different geographic areas and among different ethnic groups, similar formulae could be established using our method. After obtaining the stature formulae from the different ethnic groups, these could be used to allow for an anatomical difference. CT data is in digital form, and could be used via tele-radiology [24]. If a worldwide database of correlation of bone and stature were available, it might be easily possible to search for ethnic groups of similar physique, and decide which formula is suitable.

The first limitation of our study was the criterion which excluded ages under 20 years old, because they are in the middle of growth and their stature is changing significantly. Additionally, the stature of a neonate or of an infant can be affected by the thickness of soft tissue. Second, when the cadaver has deformation of vertebrae, such as scoliosis or gibbus, the difference between estimated height and actual stature may increase. Therefore, when this formula is adopted, it is necessary to consider estimated stature as stature when the spinal column is straight. Third, all femur measurement was done by one operator to reduce measurement error. There was no significant difference in all estimated stature using MF. If an automatic measuring tool is developed, it will be able to measure more objectively and in a short time. 
In conclusion, these regression equations using femur measurements according to the anatomical landmarks could be useful to estimate the cadaver's stature in forensic investigation, even if the femur bone was partially deteriorated.

The correlation between stature and 5 femur measurement parameters showed high correlation in the mixed-sex group, so even if it is difficult to decide the cadaver's sex, the estimated stature can be used with confidence of high correlation. 
Conflict of interest

The authors declare that they have no conflict of interest.

Funding

None declared.

Ethic approval

The study was approved by the local ethics committee and adhered to the Declaration of Helsinki.

Informed consent

Informed consent was obtained from all individual's family included in the study.

\section{Acknowledgement}

We thank Prof. Dr. Myles O’Brien (Mie Prefectural College of Nursing, Tsu, Mie, Japan) for assistance with English Language. 


\section{Reference}

[1] Nishino H. Stature Estimation Based on the Lengths of the Long Bones of the Extremities According to Post-mortem Computed Tomography. ResPractForensMed. 2013;56:223-235.

[2] Stull KE, Tise ML, Ali Z, Fowler DR. Accuracy and reliability of measurements obtained from computed tomography 3D volume rendered images. Forensic science international. 2014;238:133-140.

[3] Torimitsu S, Makino Y, Saitoh H, Sakuma A, Ishii N, Hayakawa M, et al. Stature estimation based on radial and ulnar lengths using three-dimensional images from multidetector computed tomography in a Japanese population. Legal medicine. 2014;16:181-186.

[4] Hyodoh H, Sato T, Onodera M, Washio H, Hasegawa T, Hatakenaka M. Vascular measurement changes observed using postmortem computed tomography. Jpn J Radiol. 2012;30:840-845.

[5] Hyodoh H, Shimizu J, Mizuo K, Okazaki S, Watanabe S, Inoue H. CT-guided percutaneous needle placement in forensic medicine. Legal medicine. 2015;17:79-81.

[6] Hyodoh H, Watanabe S, Katada R, Hyodoh K, Matsumoto H. Postmortem computed tomography lung findings in fatal of hypothermia. Forensic science international. 2013;231:190-194.

[7] Kanazawa A, Hyodoh H, Watanabe S, Fukuda M, Baba M, Okazaki S, et al. New pitfalls of high-density postmortem computed tomography. Legal medicine. 2014;16:297-299.

[8] Giurazza F, Del Vescovo R, Schena E, Cazzato RL, D'Agostino F, Grasso RF, et al. Stature estimation from scapular measurements by CT scan evaluation in an Italian population. Legal medicine. 2013;15:202-208.

[9] Hishmat AM, Michiue T, Sogawa N, Oritani S, Ishikawa T, Hashem MA, et al. Efficacy of automated three-dimensional image reconstruction of the femur from postmortem computed tomography data in morphometry for victim identification. Legal medicine. 2014;16:114-117. [10] Hasegawa I, Uenishi K, Fukunaga T, Kimura R, Osawa M. Stature estimation formulae from radiographically determined limb bone length in a modern Japanese population. Legal medicine. 2009;11:260-266.

[11] Mahakkanukrauh P, Khanpetch P, Prasitwattanseree S, Vichairat K, Troy Case D. Stature estimation from long bone lengths in a Thai population. Forensic science international. 2011;210:279 e1-7.

[12] Mall G, Hubig M, Buttner A, Kuznik J, Penning R, Graw M. Sex determination and estimation of stature from the long bones of the arm. Forensic science international. 2001;117:23-30. 
[13] Petrovecki V, Mayer D, Slaus M, Strinovic D, Skavic J. Prediction of stature based on radiographic measurements of cadaver long bones: a study of the Croatian population. $\mathrm{J}$ Forensic Sci. 2007;52:547-552.

[14] Torimitsu S, Makino Y, Saitoh H, Sakuma A, Ishii N, Hayakawa M, et al. Stature estimation in Japanese cadavers based on scapular measurements using multidetector computed tomography. International journal of legal medicine. 2015;129:211-218.

[15] Torimitsu S, Makino Y, Saitoh H, Sakuma A, Ishii N, Yajima D, et al. Stature estimation from skull measurements using multidetector computed tomographic images: A Japanese forensic sample. Legal medicine. 2016;18:75-80.

[16] Hishmat AM, Michiue T, Sogawa N, Oritani S, Ishikawa T, Fawzy IA, et al. Virtual CT morphometry of lower limb long bones for estimation of the sex and stature using postmortem Japanese adult data in forensic identification. International journal of legal medicine. 2015;129:1173-1182.

[17] Ahmed AA. Estimation of stature using lower limb measurements in Sudanese Arabs. J Forensic Leg Med. 2013;20:483-488.

[18] Krishan K, Kanchan T, Asha N. Estimation of stature from index and ring finger length in a North Indian adolescent population. J Forensic Leg Med. 2012;19:285-90.

[19] Nor FM, Abdullah N, Mustapa AM, Qi Wen L, Faisal NA, Ahmad Nazari DA. Estimation of stature by using lower limb dimensions in the Malaysian population. J Forensic Leg Med. 2013;20:947-952.

[20] Ozaslan A, Iscan MY, Ozaslan I, Tugcu H, Koc S. Estimation of stature from body parts. Forensic science international. 2003;132:40-45.

[21] Farsinejad M, Rasaneh S, Zamani N, Jamshidi F. Relationship between the stature and the length of long bones measured from the X-rays; modified trotter and gleser formulae in iranian population: A preliminary report. Soud Lek. 2014;59:20-22.

[22] Mladenovic AS, Markovic ZZ, Hyodoh HH. Anatomic differences of the distal aorta with dilatation or aneurysm between patients from Asia and Europe as seen on CT imaging. Eur J Radiol. 2012;81:1990-1997.

[23] Pininski M, Brits D. Estimating stature in South African populations using various measures of the sacrum. Forensic science international. 2014;234:182 e1-7.

[24] Coulombe P, Qualls C, Kruszynski R, Nerlich A, Bianucci R, Harris R, et al. Network science in Egyptology. PLoS One. 2012;7:e50382. 